\title{
Embryonic Assembly of a Complex Muscle Is Directed by a Single Identified Cell in the Medicinal Leech
}

\author{
John Jellies and William B. Kristan, Jr. \\ Department of Biology, University of California at San Diego, La Jolla, California 92093
}

\begin{abstract}
The present study examines the morphological development of a highly organized muscle layer in the leech Hirudo medicinalis, in an effort to characterize those factors that are important in directing its assembly. The tubular body wall of the leech contains 3 major muscle layers that are anatomically distinct: an inner layer of longitudinal muscle, an outer layer of circular muscle, and a grid of oblique muscle sandwiched between them. The oblique muscle layer appears later in development than the other 2 and is preceded by several days by the development of a single, complex cell (here called the comb, or C-cell) whose shape strongly resembles the organization of the oblique muscle grid. There is a bilateral, mirror-image pair of $C$-cells in each segment. The C-cell has a central, longitudinally oriented soma and projects about 35 fine, parallel processes both medially and laterally at approximately $45^{\circ}$ to the long axis. Using a combination of intracellular and antibody labels, it was found that individual muscle cells align themselves with these processes to form correctly oriented fascicles during development. Photoablation of the C-cell at early stages resulted in the complete absence of all oblique muscle fascicles that would have corresponded to that cell; therefore, this discrete muscle-associated cell is considered to be an identified "muscle organizer." Such cellular organizers may direct muscular and neuromuscular assembly in many species.
\end{abstract}

Although there is a considerable body of evidence indicating that the expression of particular phenotypes in muscle cells results from nerve-muscle interactions (Buller et al., 1960; Rubinstein and Kelly, 1978, 1981; Butler and Cosmos, 1981; Bennett, 1983; McLennan, 1983a, b), recent studies have shown that certain properties of muscle once thought to be determined by trophic interactions with nerve cells can arise independently of neuronal influences (Butler et al., 1982; Crow and Stockdale, 1986; Sanes, 1987; Vogel and Landmesser, 1987) and in a seemingly lineage-dependent fashion (Miller and Stockdale, 1986a, b, 1987; Schafer et al., 1987). Therefore, the development of motoneurons and the muscles they innervate appears to exhibit a significant degree of independence. The matching of neurons to appropriate target muscles probably involves specific rec-

\footnotetext{
Received Aug. 24, 1987; revised Nov. 25, 1987; accepted Nov. 27, 1987.

We wish to thank K. French for helpful comments on this manuscript, C. Loer for helpful discussions, S. Reynolds and S. Furgal for technical assistance, and B. Zipser for kindly providing the monoclonal antibody Lan 3-14. This work was supported by an NIH fellowship (NS 07684) to J.J. and an N1H grant (NS 20746) to W.B.K.

Correspondence should be addressed to John Jellies, Department of Biology, B-022, UCSD, La Jolla, CA 92093.

Copyright (C) 1988 Society for Neuroscience $0270-6474 / 88 / 093317-10 \$ 02.00 / 0$
}

ognition of a muscle's identity by the motoneurons, as well as instructive and/or permissive interactions (Landmesser, 1980; Bennett, 1983). Seen in this light, one of the fundamental problems in understanding the generation of neuromuscular specificity is to determine how muscles develop in particular places with characteristic features that can be recognized by developing neurons (Ball et al., 1985a).

We are concerned not only with how muscles come to be innervated in highly specific ways, but also with how the muscles acquire their particular biochemical phenotypes, positions, and overall organization. Vertebrate muscles arise during embryogenesis by a process of migration of the precursors to appropriate locations, followed by fusion of myoblasts, synthesis of muscle proteins, and splitting of myotubes (Stockdale and Holtzer, 1961; Kelly and Zacks, 1969; Chevallier et al., 1977; Ontell, 1977; Ontell and Dunn, 1978; Dennis et al., 1981; Harris, 1981; Beresford, 1983). These events are largely paralleled by myogenesis in invertebrates (Denburg and Fulop, 1982; Lawrence and Brower, 1982; Pearson and Epstein, 1982; Ball and Goodman, 1985a, b; Ball et al., 1985b; Costello and Wyman, 1986).

The work described here concerns the development of one muscle layer in the leech Hirudo medicinalis, and takes advantage of the animal's relatively simple neuromuscular organization. Leeches have a segmentally repeated body plan (Muller et al., 1981), including a system of highly organized muscles innervated in very specific ways by a limited number of identified motoneurons (Stuart, 1969, 1970; Ort et al., 1974). In addition to having individually identified neurons, the leech contains individually identified muscle cells (Coggeshall and Fawcett, 1964; Tulsi and Coggeshall, 1971) and distinct muscle layers in the body wall (Sawyer, 1986), making this an attractive system in which to examine the embryonic assembly of muscles.

In this paper, we examine the morphogenesis of the oblique muscles in the body wall. There is a single, bilateral pair of identified cells with a highly organized structure in the body wall of each segment, whose development precedes the appearance of the oblique muscles and which serves as a scaffold on which to erect a grid of oblique muscle fascicles. This peripheral cell is anatomically distinct from the muscles themselves, and killing it prior to the appearance of the muscles results in a specific and absolute loss of oblique muscle organization.

\section{Materials and Methods}

Animals. Embryos of the medicinal leech Hirudo medicinalis were obtained from a laboratory breeding colony (Jellies et al., 1987) and staged in days of development at $22-24^{\circ} \mathrm{C}$, as previously described (Fernandez and Stent, 1982).

Indirect muscle staining. Staining of dissected and fixed embryos was accomplished using methods detailed elsewhere (Jellies and Kristan, 


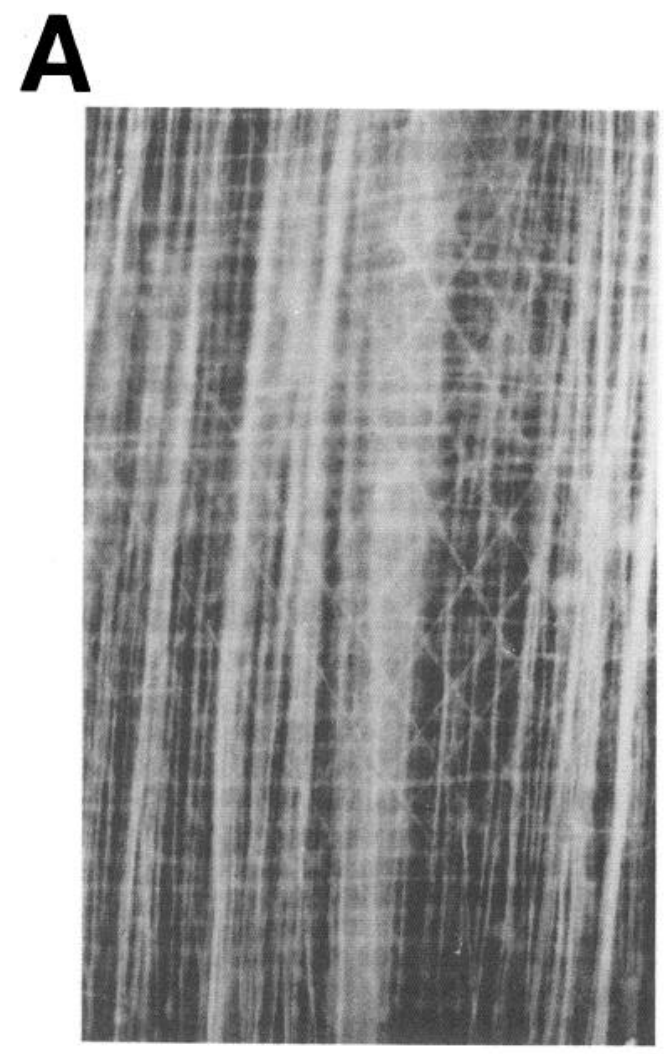

B

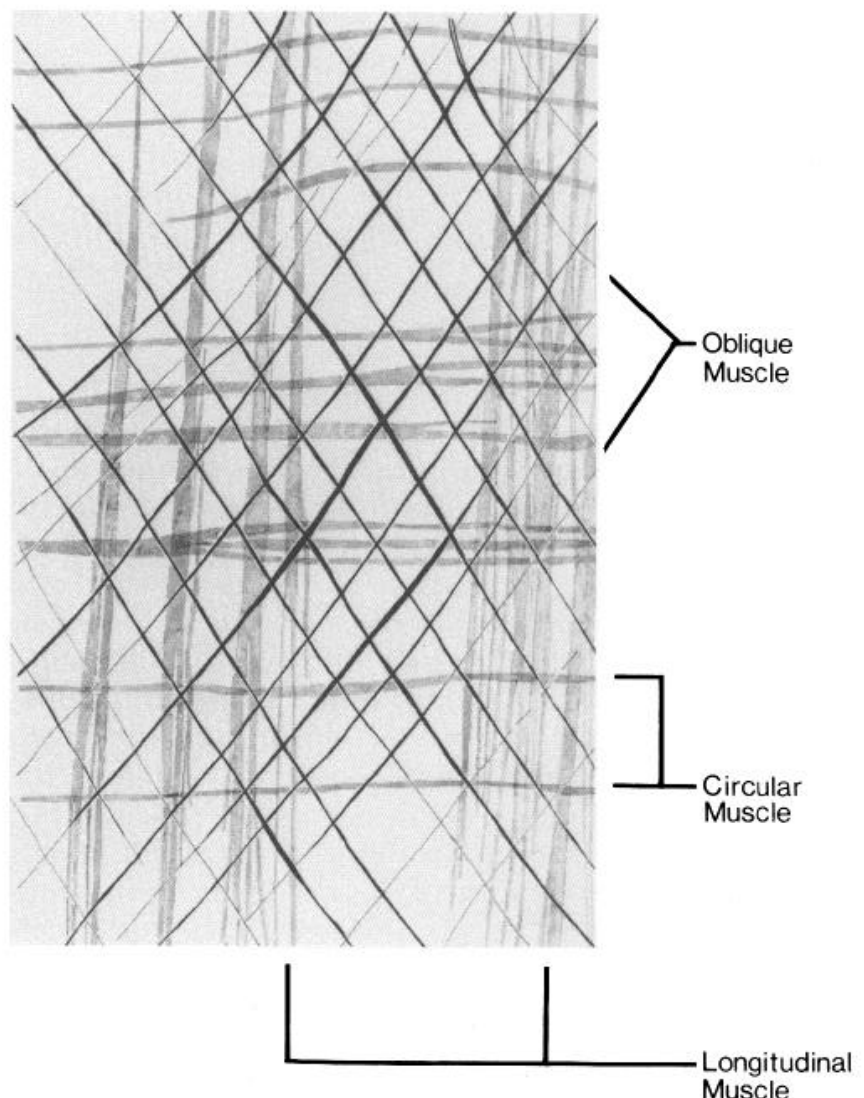

Figure 1. The leech body wall contains 3 anatomically distinct layers of muscle. A, Negative image of a portion of the body wall from a 20-dold embryo stained with the monoclonal antibody Lan 3-14 (Zipser and McKay, 1981). B. Diagrammatic version of the staining in $A$. Only a few of the longitudinal and circular muscles are drawn (gray), while all of the oblique muscle fascicles are drawn (black). There are no actual breaks in the fascicles (seen in upper left); this appearance results from not being able to focus all regions of the field. Anterior is upward; calibration, $100 \mu \mathrm{m}$.

1988). Briefly, embryos were fixed overnight (cold) in $4 \%$ paraformaldehyde in $0.1 \mathrm{M}$ phosphate buffer ( $\mathrm{pH} 7.4$ ), rinsed several times in PBS, and then incubated in the $1^{\circ}$ antibody overnight at room temperature $\left(22-24^{\circ} \mathrm{C}\right)$. Muscles were visualized by applying a monoclonal antibody (Lan 3-14) that recognizes an unidentified antigen associated with leech muscle cells (Zipser and McKay, 1981). Lan 3-14 ascites fluid was diluted 1:200-1:500 with PBS containing 1\% goat serum, 2\% Triton $\mathrm{X}-100$, and $0.1 \%$ sodium azide. After rinsing in PBS for $2-4 \mathrm{hr}$, the tissues were incubated in TRITC-conjugated goat anti-mouse IgG (Cappel Worthington Biochemicals, Malvern, PA) diluted 1:200 in PBS that contained $1 \%$ goat serum and $2 \%$ Triton for $2-4 \mathrm{hr}$ at room temperature. The rhodamine label was visualized on a Zeiss epifluorescent microscope using Zeiss filter set 48-77-12. Fluorescently stained preparations were dehydrated in a graded ethanol series and mounted in Gurr Fluoromount (BDH Chemicals, Poole, England).

Severe access problems in older tissues limited the usefulness of the muscle antibody. Therefore, in order to visualize oblique muscles in 90-d-old juveniles, they were stained nonspecifically using Evan's blue (EB; Sigma, St. Louis, MO). Dissected animals were fixed in $4 \%$ paraformaldehyde for 2-4 hr, rinsed in PBS several times, then immersed in PBS that contained 2\% EB for 30-60 min. After rinsing again in PBS, the tissues were destained in $70 \%$ ethanol for $30-60 \mathrm{~min}$, rinsed in PBS, and reimmersed in the EB solution for 30-60 min. After this second staining, tissues were washed in PBS, dehydrated in a graded ethanol series, and mounted in Permount (Fisher, Fair Lawn, NJ).

Counting oblique muscle fascicles was carried out using a $40 \times$ objective and differential interference contrast (DIC) optics. For counting, a single segment was arbitrarily defined as the region between the anterior margins of adjacent ganglia. Oblique muscle fascicles were counted in midbody segments $2-8$.
Intracellular staining. Individual cells in the body wall were visualized by injecting them with HRP or various fluorescent dyes. In every case, animals were dissected in leech saline (Muller et al., 1981) that contained $8 \%$ ethanol in order to narcotize them, then pinned to a glass slide that was covered with a thin layer of Sylgard resin (Dow Corning, Midland, MI).

Cells to be injected were located visually using DIC optics. Muscle cells could be seen easily and were identified by their locations, their morphology, and the very slight (in $8 \%$ ethanol), but visible contractions they produced when impaled. The C-cell was identified by its large size, as well as by its characteristic shape and location (see Results). Cells were impaled with glass microelectrodes directly through the transparent epidermis of the embryo.

HRP (Sigma grade VI) was prepared as a $3 \%$ solution in $0.2 \mathrm{M} \mathrm{KCl}$ that contained $2 \%$ fast green. This solution was pressure-injected into cells, as described previously (Jellies et al., 1987). Following injection, embryos were transferred to L-15 medium at room temperature for 1 $\mathrm{hr}$, allowing the enzyme to diffuse. The preparations were then relaxed in $8 \%$ ethanol/saline, repinned, and fixed in cold $2 \%$ paraformaldehyde, $2 \%$ glutaraldehyde in $0.1 \mathrm{~m}$ phosphate buffer ( $\mathrm{pH} \mathrm{7.4)}$ for 30-60 min, then rinsed in PBS and developed using diaminobenzidene (Organon Teknika, Durham, NC), $\mathrm{H}_{2} \mathrm{O}_{2}$, and cobalt intensification (Gillon and Wallace, 1984). Completed preparations were dehydrated in a graded ethanol series and mounted in Permount.

Lucifer yellow $\mathrm{CH}$ (Sigma) was prepared as a $3 \%$ aqueous solution (Stewart, 1978), and injected by passing constant hyperpolarizing current $(0.2-1.0 \mathrm{nA})$ through the microelectrode $(200-400 \mathrm{M} \Omega)$ for $1-3$ $\mathrm{min}$. The dye spread throughout the injected cells rapidly, within $5 \mathrm{~min}$ from the start of filling. These preparations were fixed in $4 \%$ paraformaldehyde for 30-60 min, rinsed in PBS, and dehydrated and mounted 
A

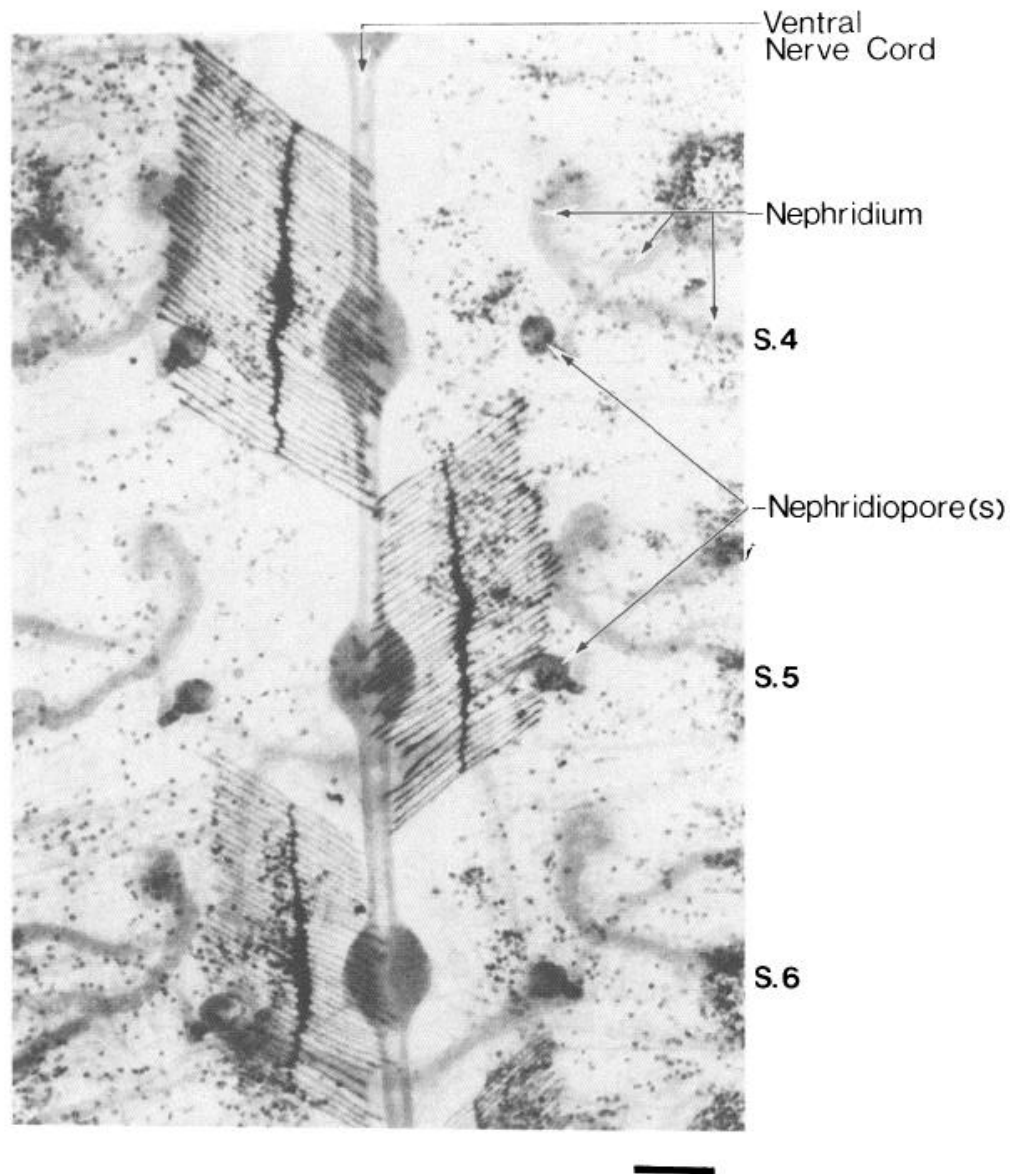

B

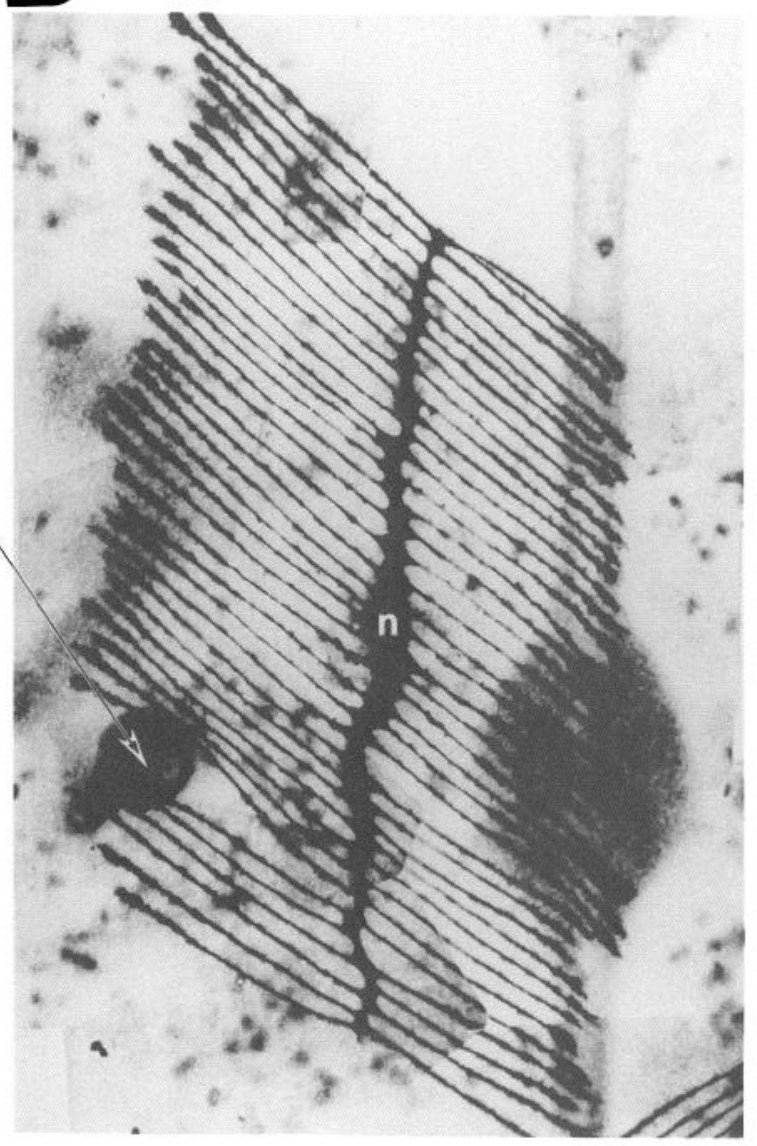

Figure 2. Mirror-image C-cells reside in the body wall. A, Central portion of 3 midbody segments (S. 4, 5, and 6) from a 12-d-old embryo. The ventral nerve cord is composed of a chain of ganglia, 1/segment, each containing approximately 200 different neuronal somata (Macagno, 1980). This nerve cord lies along the ventral midline. Portions of the nephridia (a single nephridium is indicated) and nephridiopores are shown as convenient landmarks. The male and female reproductive tissues can be seen faintly at the ventral midlines of S. 5 and S. 6, respectively (Jellies et al., 1987). A single C-cell per segment, on alternating sides, was filled with HRP. B. Close-up photomontage of the filled C-cell seen in S. 4 in $A$. $n$, The position of the nucleus, which cannot be seen in this darkly stained cell. This and all other intracellular stains were photographed through the clear epidermis of the embryo. Anterior is up; both calibrations, $100 \mu \mathrm{m}$.

as described earlier. Lucifer yellow was visualized using Zeiss filter set 48-77-07. When embryos with Lucifer-filled cells were to be labeled with the muscle antibody, they were fixed overnight and then processed as described earlier, except that no azide was used.

Two additional fluorescent dyes were used in conjunction with Lucifer yellow. The first, sulforhodamine 101 (Molecular Probes, Junction City, OR), was prepared as a $2 \%$ aqueous solution and injected through microelectrodes in the same manner as was Lucifer. This red-fluorescent molecule was visualized using the rhodamine filter set (Zeiss 48-77-12). The second dye, 8-hydroxy-1,3,6-pyrenetrisulfonic acid, trisodium salt (Eastman Kodak, Rochester, NY), was prepared as a 3\% aqueous solution and injected with hyperpolarizing current as were the others. This blue-fluorescent molecule was visualized with Zeiss filter set 48-77-02, normally used to view Hoechst stain. These 2 dyes have been used to label electrically active endplates at the vertebrate neuromuscular junction (Lichtman et al., 1985), a technique that has not worked using $H$. medicinalis (S. Lockery and G. Wittenberg, personal communication, and unpublished observations).

Preparations using these additional fluorescent dyes were photographed within $1 \mathrm{hr}$ of filling, since these dyes were not fixable and diffused out of the cells within 12-24 hr. To do this, embryos bearing injected cells were fixed in $4 \%$ paraformaldehyde for $10 \mathrm{~min}$, rinsed in
PBS, and photographed hydrated and uncleared. Multiple exposures were made on Ektachrome color slide film (Daylight, ASA 200) by sequentially exposing the film through the different filter sets, maintaining the preparation at the same field of view and focal plane.

Photoablations. Individual C-cells in 11-d-old embryos were killed by exposure to UV light after being filled with Lucifer yellow (Miller and Selverston, 1979). For this procedure, whole, living embryos were first anesthetized in "embryo water" (Jellies et al., 1987) with $12 \%$ ethanol. The embryos were placed in a depression cut from a Sylgardcoated petri dish (germinal plate upward) and viewed using transmitted light. A C-cell soma was identified visually, impaled, and filled with Lucifer. The preparation was then exposed to UV light through the Lucifer filter set for 3-6 min to kill the filled cell (see Results; Fig. 6). Operated embryos were allowed to develop for an additional 5-9 d in individual dishes containing normal embryo water, after which they were dissected and examined using Lan 3-14 for muscle deficiencies.

Terminal lineage tracing. The possibility that the C-cell might serve as a precursor for muscle cells was studied by injecting HRP into it and examining the preparations after several days of development for the location of HRP reaction product (Weisblat et al., 1978). Whole, living embryos (at 11 and $12 \mathrm{~d}$ of development) were immobilized as previously described, and individual C-cells were identified visually. HRP 


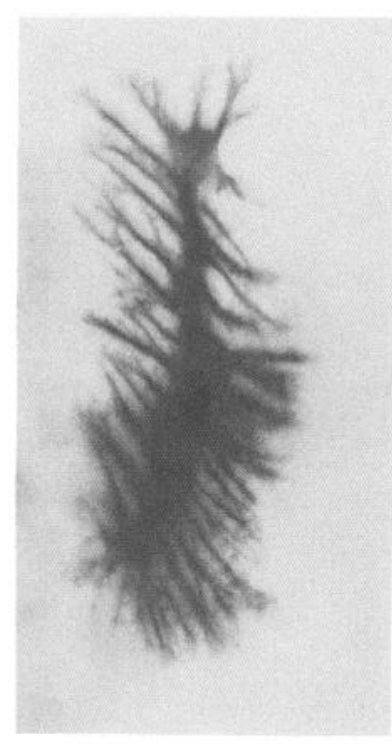

S.5

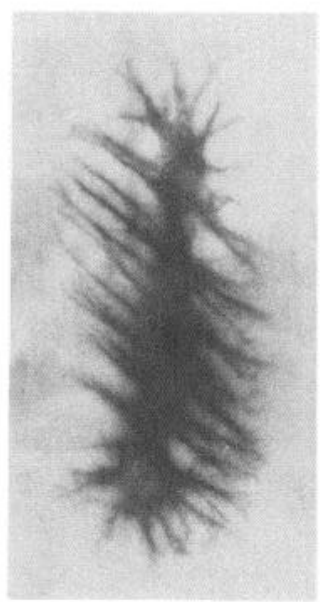

S.8

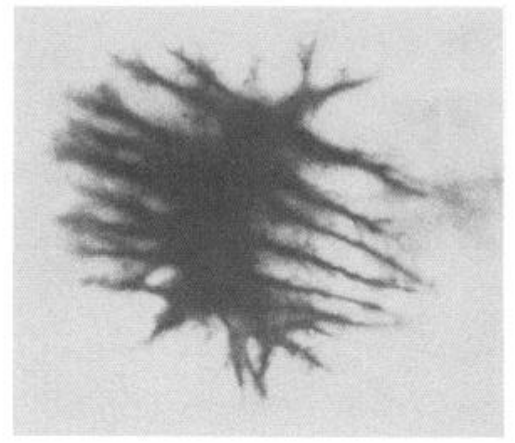

S. 12

Figure 3. Early morphogenesis of the C-cell is revealed by the rostrocaudal gradient of development. Negative images of Lucifer yellow-filled $\mathrm{C}$-cells from segments 5, 8, and 12 of an individual 9-d-old embryo. The ventral midline is to the right of each image. Anterior is up; calibration, $100 \mu \mathrm{m}$.

was pressure-injected into C-cells, and each animal was then allowed to develop for 2-4 d, after which it was dissected and processed to develop the HRP reaction product, as previously described.

\section{Results}

\section{Oblique muscle organization}

The major muscular components of the $H$. medicinalis body wall were visualized by using a monoclonal antibody that recognizes leech muscle (Zipser and McKay, 1981) (Fig. 1). The muscles occur in 3 anatomically distinct layers (Sawyer, 1986): an inner layer of longitudinal muscles (parallel to the long axis), an outer layer of circular muscles (circumferential or perpendicular to the long axis), and an orthogonal grid of oblique muscles (oriented at approximately $45^{\circ}$ to the long axis) that is sandwiched in-between.

In older leeches, the oblique muscle layer is thinner and less dense than the other 2 layers. In each midbody segment, it consists of 35 separate fascicles running in each direction (in 90-d-old juveniles, 34.82 $\pm 0.25, n=40$; in 17-d-old embryos, $35.09 \pm 0.35, n=46$; values are \pm SEM). The oblique muscles begin to appear relatively late in embryogenesis, as determined by antibody staining. Scattered fascicles with the proper orientation were first seen late in day 12 of embryogenesis, well after the rudiments of the longitudinal and circular muscle layers had begun to differentiate (Torrence and Stuart, 1986). The staining was at first limited to the central region of the germinal plate (the area between the nephridiopores), and was found to expand toward the edges of the germinal plate over the next 7 d. This temporal pattern of antibody staining correlated well with our ability to identify oblique muscle cells in live, unstained embryos using DIC optics.
Since this oblique layer of muscle appeared relatively late in embryonic life and assembled itself into a complex, gridlike organization at its earliest appearance, we wished to determine what cue or cues might be directing this assembly.

\section{The comb cell}

The striking morphology of a particular set of cells found in the body wall of embryonic $H$. medicinalis suggested that they might play a role in organizing the formation of the complex oblique muscle layer. This peripheral cell type, here called the comb or C-cell, has a structure reminiscent of oblique muscle organization (Fig. 2), at most stages resembling a double-sided comb. The C-cell was found as a bilateral pair of mirror-image cells in each of the 21 midbody segments, as well as in the first segment of the head. Each $\mathrm{C}$-cell had a central spindle-shaped region (the cell soma) aligned with the long axis and a single large nucleus located at the center of this spindle. The soma was found about midway between the ventral midline and the nephridiopore (Fig. $2 A$ ) and was easily seen with DIC optics.

A large number of finer parallel processes arose from the soma. These processes were oriented at approximately $45^{\circ}$ to the long axis. For simplicity of discussion, processes initially directed toward the ventral midline are called medial, while those directed toward the lateral midline are called lateral. The medial processes always pointed toward the posterior, and the lateral processes always pointed anteriorly (Fig. $2 B$ ). Each long, thin process terminated in a large spatulate structure with numerous filopodia, strongly resembling a neuronal growth cone (Fig. 2B). The detailed morphogenesis of these cells and the behavior of the growth cones will be considered elsewhere. What follows is a brief description of the morphological changes ob- 
served in the C-cell during embryogenesis, which is intended to place the chronology of C-cell development in context with the appearance of the oblique muscles.

\section{C-Cell morphogenesis}

The C-cell was first identified in the most anterior segments during the last third of embryonic day 8 . At this stage the soma was located approximately where it will be found later. Whether it arises in this location because of its lineage (which is presently not known) or because it migrates to this location from elsewhere (Torrence and Stuart, 1986) is not known. At this earliest stage, the $\mathrm{C}$-cell is truncated, having only about 12 short processes, 6 on each side.

The earliest morphological changes were examined by taking advantage of the rostrocaudal gradient of development, where the most anterior cells of the germinal plate are the developmentally most advanced (Stent et al., 1982). The C-cell in segment 12 of a 9-d-old embryo closely resembled the more anterior (for example, segments 3-5) C-cells of an 8-d-old embryo (Fig. 3). The soma of the C-cell progressively elongated axially while, or as a result of, adding processes. It appears that processes were added primarily at the anterior and posterior ends of the elongating soma, since shorter, poorly oriented (nonoblique) processes were located here (Fig. 3). During these early stages, there appeared to be little or no elongation of the medial and lateral processes (Fig. 3).

The addition of processes in anterior segments continued through day 10 of embryogenesis. During the last third of day 10 and into day 11 , the processes began to elongate. By day 12 of embryogenesis, the advancing fronts of growth cones from contralateral homologs had met at the ventral midline (Fig. 2A), and by day 14 the medial growth cones had reached the contralateral nephridiopores, while the lateral growth cones reached the future lateral midline. This elongation of fine processes continued through days 18-20. On about day 20 , the growth cones reached the edges of the germinal plate, and the margins of the germinal plate were fusing along the dorsal midline. (For an overview of germinal plate development in $H$. medicinalis, see Fernandez and Stent, 1982.)

\section{The relationship between $C$-cells and oblique muscles}

From the beginning of the development of the oblique muscle layer, a close association was apparent between C-cells and these muscle cells. When the crossing-over of contralateral C-cell processes is examined (Fig. 4), one sees a strikingly regular grid that strongly resembles the organization of oblique muscles (compare Fig. 4 to Fig. 1). Each C-cell in segments $2-8$ of $12-15$-d-old embryos had 35.65 processes $( \pm 0.44, n=80)$ on a side, a number not significantly different from the number of oblique muscle fascicles per segment in advanced embryos and juveniles (Student's $t$ test; $p \leq 0.05$ ).

Furthermore, the development of the C-cell was observed to precede that of the oblique muscle layer at all stages. Oblique muscle cells were first seen during day 12 of embryogenesis, about $80 \mathrm{hr}$ after the appearance of the $\mathrm{C}$-cell as a recognizable entity. Oblique muscle cells were added in concert with the subsequent growth of C-cell processes, first in the ventral region of the germinal plate and later more laterally. By labeling the muscle cells with the Lan 3-14 antibody and filling C-cells with Lucifer yellow, we found that $\mathrm{C}$-cell processes always preceded the appearance of oblique staining. In all cases $(n=33 \mathrm{C}$-cells

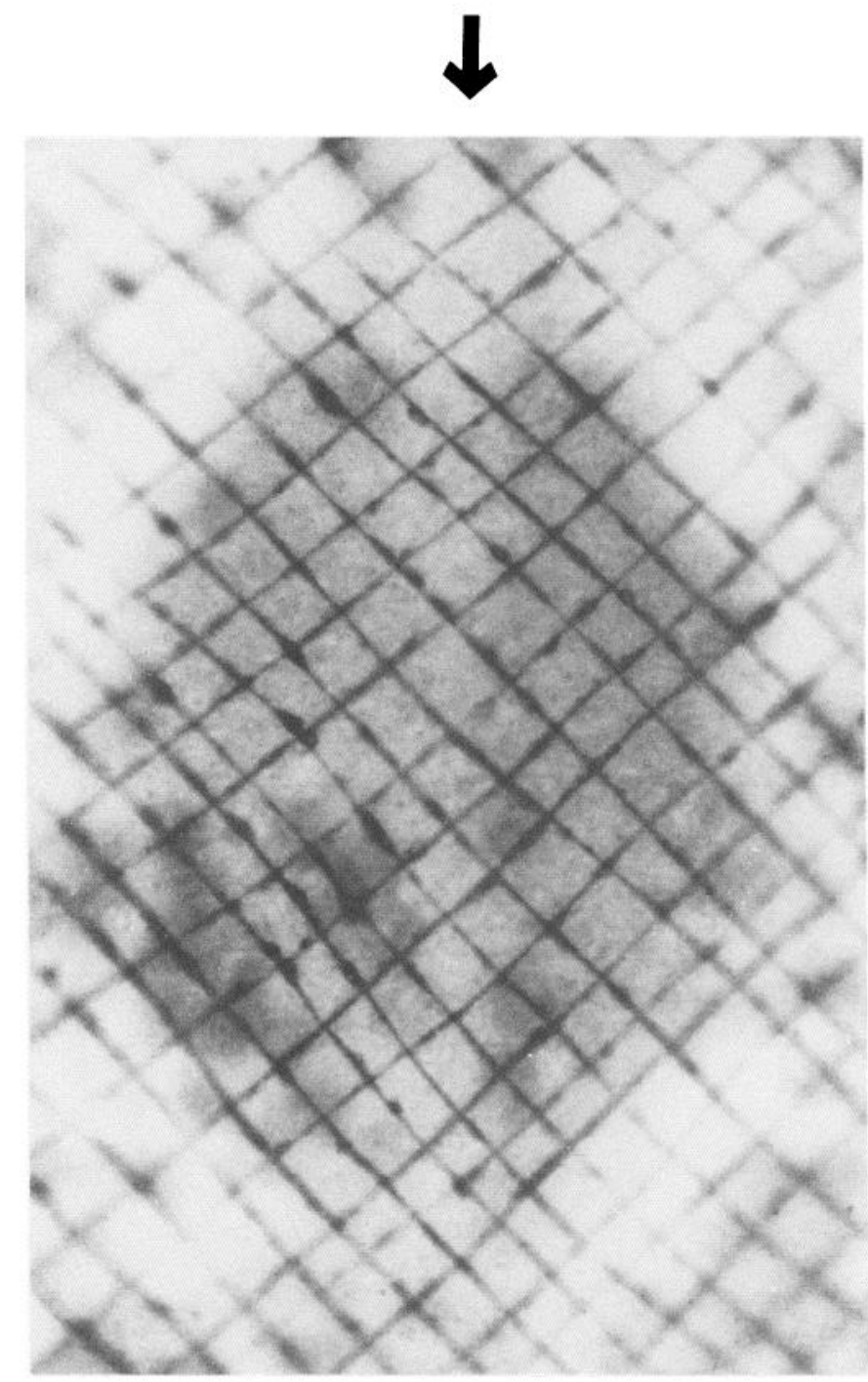

Figure 4. Processes from contralateral C-cells cross to form an orthogonal grid. This is a closeup view at the ventral midline (arrow) of a 14-d-old embryo in which a pair of contralateral C-cells was filled with HRP. The out-of-focus shadow of ganglion 4 can be seen. The beaded appearance of some processes is probably the result of organelles within the fine processes, rather than of injection artifacts, because most of the beads have translucent centers and smooth, apparently intact boundaries. Anterior is up; calibration, $50 \mu \mathrm{m}$.

in 16 animals, 14-18 d old), the C-cell was distinct from the oblique muscle cells: the C-cell processes, unstained with the antibody, were always closely associated with stained fascicles of oblique muscle (Fig. $5 A$ ).

The relationship between particular muscle cells and the C-cell was examined directly in order to eliminate the ambiguities inherent in more indirect observations. To do this, C-cells and various individual muscle cells in the same embryo were filled with dyes that fluoresce at significantly different wavelengths (see Materials and Methods). In these preparations, the C-cell processes were clearly associated with oblique muscle cells and not associated at all with longitudinal and circular muscle cells (Fig. 5B). The oblique muscle cells line up adjacent to $\mathrm{C}$-cell processes, following them closely, even mirroring small devia- 

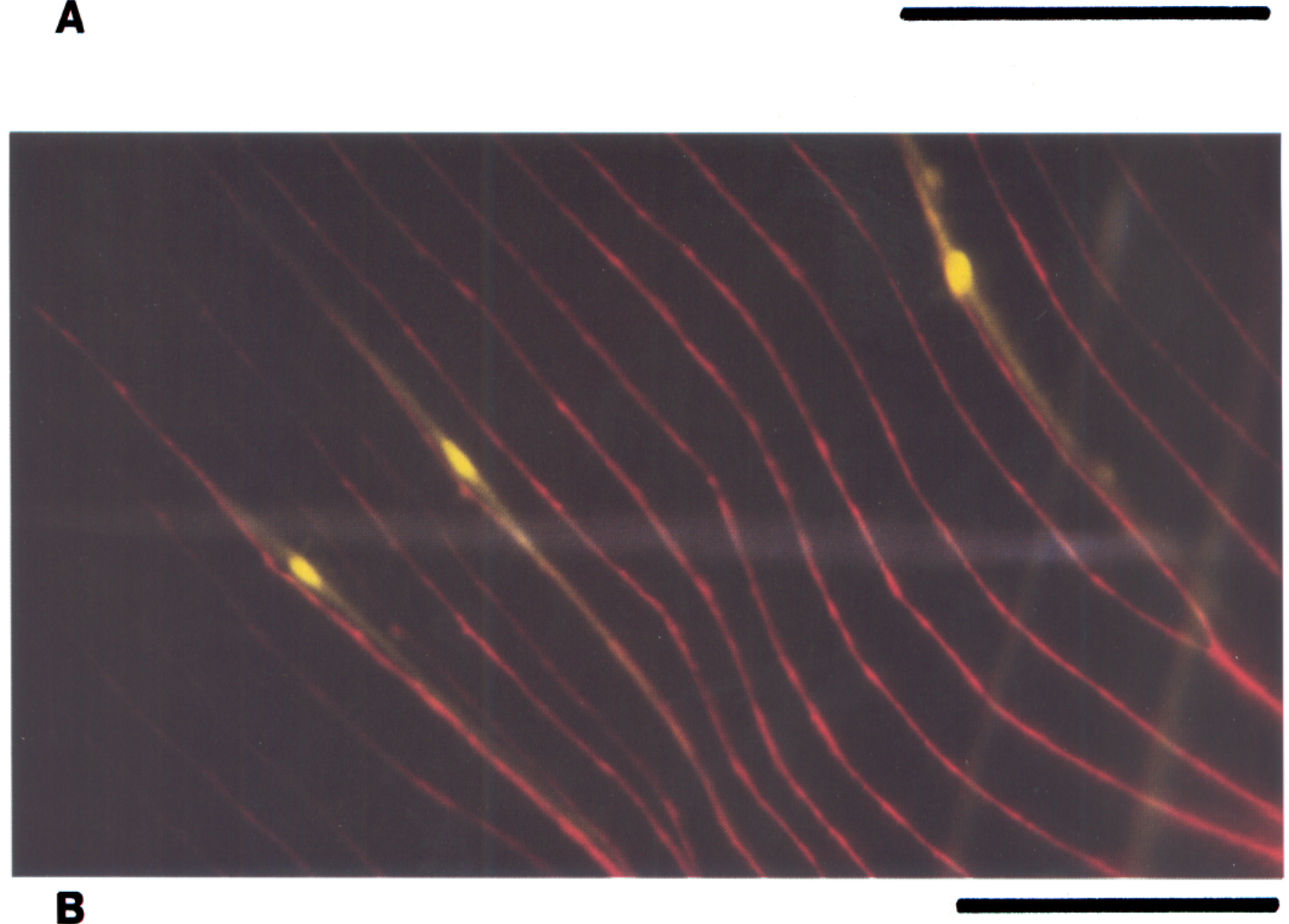

B 


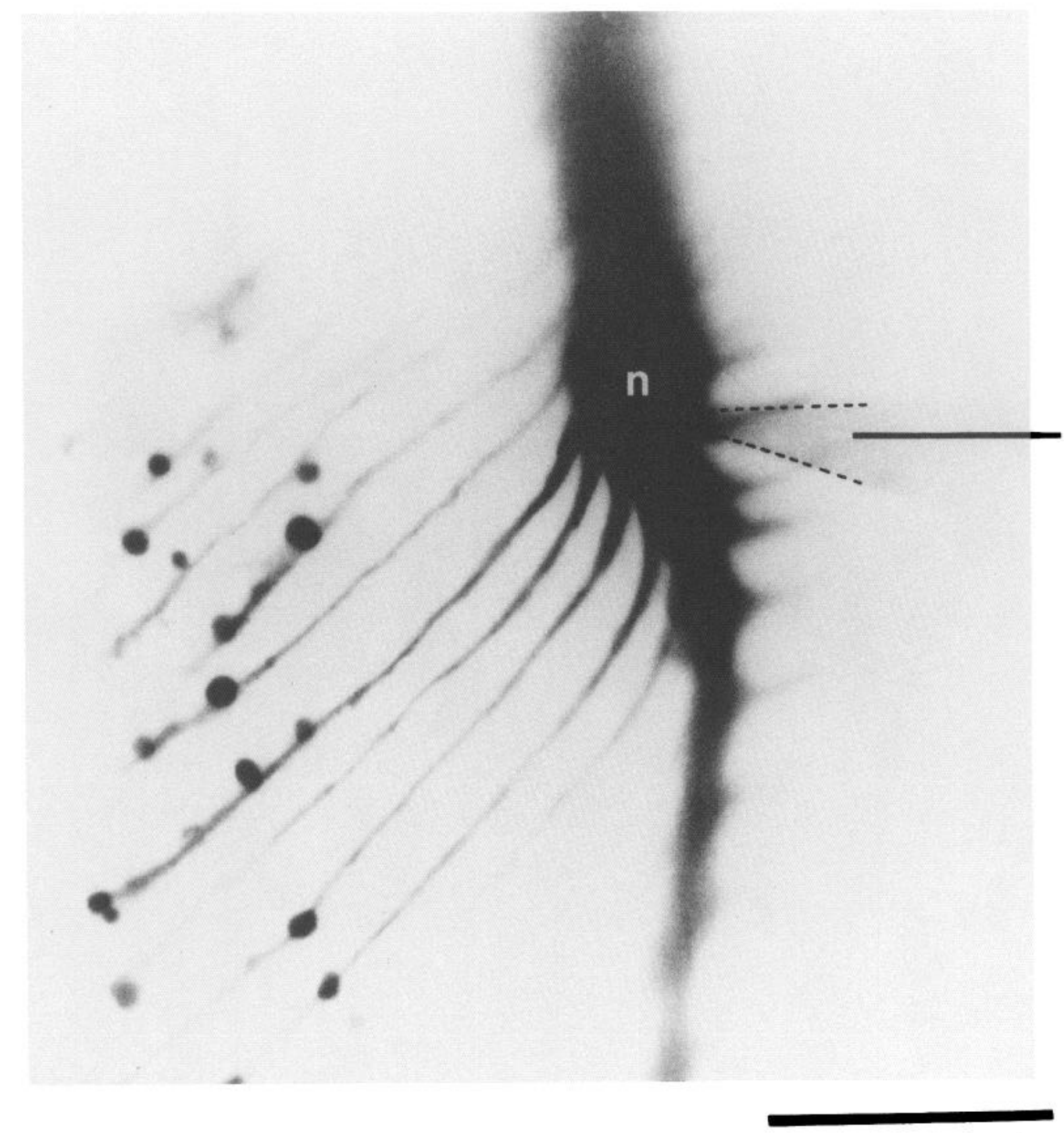

Figure 6. Photoablation of individual C-cells in live embryos by exposure to UV irradiation after filling them with Lucifer yellow. This is a negative image of a Lucifer-filled C-cell in a live embryo after approximately $30 \mathrm{sec}$ exposure to UV. Lucifer dye had begun to leak very rapidly from the processes, as indicated by the strongly beaded appearance. This beading was found to spread over the entire cell over the course of a few minutes' exposure. $n$, Nucleus. The fluorescent shadow of the microelectrode can be seen faintly (dotted lines). The photograph is slightly blurred because the animal was making slow movements and undulating during the long photographic exposure required. Anterior is up; calibration, $50 \mu \mathrm{m}$.

tions in orientation. Although only a few oblique muscle cells were filled in any one preparation, there are actually many of them and they are aligned along the $\mathrm{C}$-cell processes end-to-end and often overlapping. It is this collection of discrete muscle cells that forms the muscle fascicle one sees using the muscle antibody.

\section{C-Cell ablations}

The evidence described above establishes a close developmental relationship between the morphogenesis of the $\mathrm{C}$-cell and the complex layer of oblique muscle. In order to examine the importance of this relationship, individual C-cells were ablated at a stage before the appearance of the oblique muscle layer, and the subsequent formation of this muscle in the absence of the $\mathrm{C}$-cell was assessed. This procedure was accomplished by photoablation of a C-cell after filling it with Lucifer yellow (see Materials and Methods) in an otherwise intact embryo. This treatment very specifically killed individual C-cells, causing them to become granular and presumably rapidly disrupting the cell membrane, as evidenced by a beaded appearance along their

Figure 5. C-cell processes and oblique muscle are closely associated. $A$, Double label using Lan 3-14 to stain body wall muscles, and Lucifer yellow injection of a C-cell in a 17-d-old embryo. The faint red staining of oblique muscle fascicles is parallel and adjacent to individual C-cell processes. Additionally, the Lan 3-14 staining of muscle is distinct from the C-cell itself, which does not stain with the antibody. Anterior is to the left; calibration, $20 \mu \mathrm{m}$. B. Triple label by intracellular injections using 3 fluorescent dyes in a 14-d-old embryo. The C-cell is red, 1 circular and 2 longitudinal muscle cells are blue, and 3 oblique muscle cells are yellow. The oblique cell seen in the upper right was weakly dye-coupled to 2 others. The preparation was pinned slightly askew so that the longitudinal and circular muscle cells do not appear perpendicular to one another. Anterior is up; calibration, $100 \mu \mathrm{m}$. 
Figure 7. The result of killing a single C-cell early in development (see text). Left, Three adjacent segments; the diagonal lines represent oblique muscle fascicles (only $5 /$ segment are drawn). The location of C-cells is indicated by the faint, hollow rectangles, the C-cell to the right of center was ablated, and the deficit in oblique muscle corresponds to the missing C-cell. Right, Negative images of Lan 3-14 staining of comparable locations in an unoperated (upper) and the operated (lower) segment in the same animal. The lower photograph is slightly overexposed. The C-cell contralateral to the one ablated was able to organize its muscular components normally, demonstrating that prolonged exposure to UV had no overt deleterious effects on this process. Anterior is up; calibration, $100 \mu \mathrm{m}$.

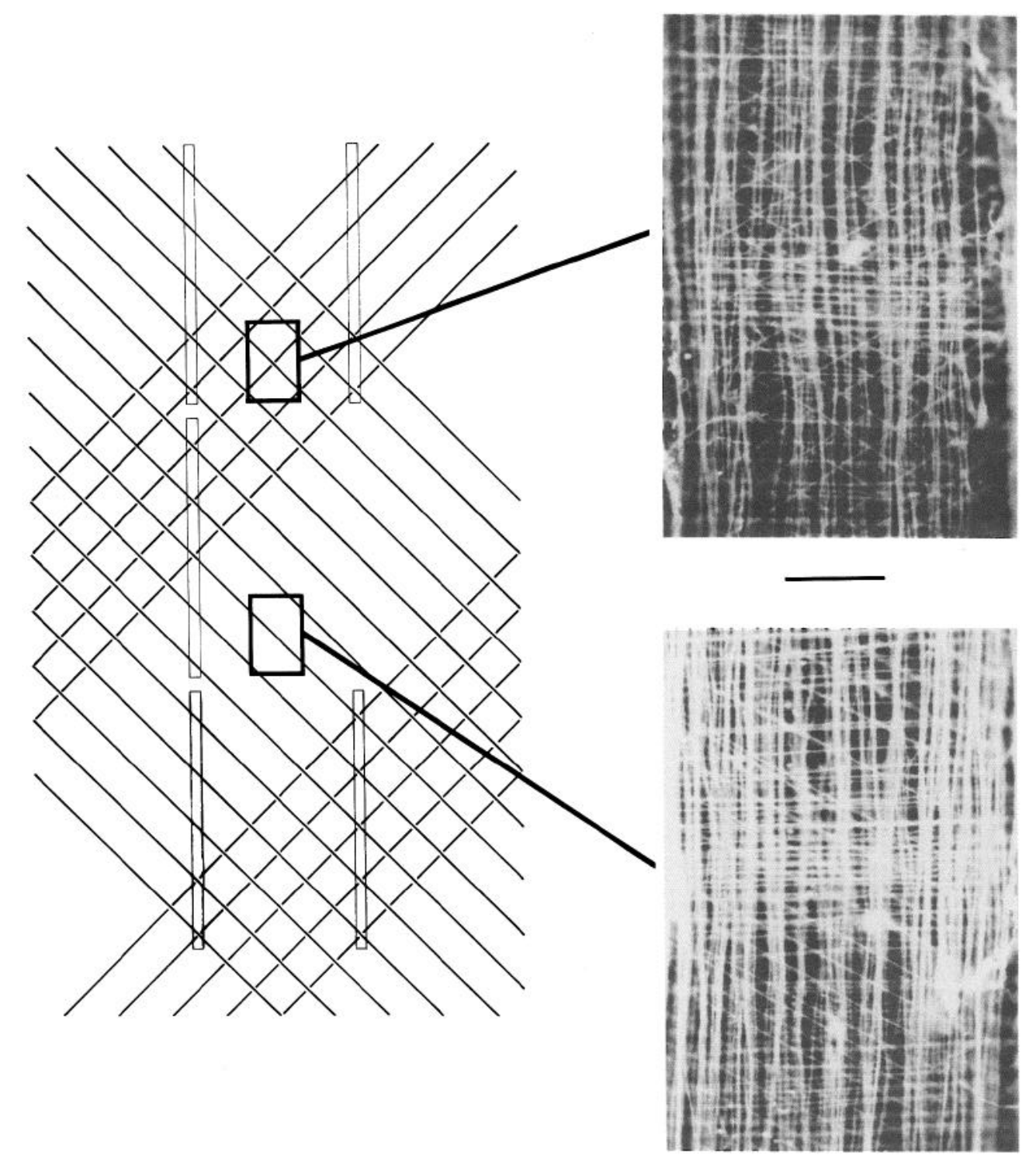

processes (Fig. 6) that spread quickly over the entire cell. When such preparations were examined $24 \mathrm{hr}$ later, the injected C-cell was missing, with only a few widely scattered fragments of Lucifer-stained membrane visible. Contralateral C-cells were left uninjected as a control for normal oblique muscle assembly after exposure to UV irradiation.

The treated embryos were allowed to develop further for 5$9 \mathrm{~d}$, when they were examined using the muscle monoclonal antibody. Thirty-nine ablations of C-cells in segments 4-7 were performed in individual embryos (1/animal); 36 of these embryos survived at least $5 \mathrm{~d}$. Every animal had the same, highly specific deficit in oblique muscle cells (Fig. 7): all of the oblique muscle fascicles that would have corresponded to the processes of the ablated C-cell were missing entirely, while those corresponding to the contralateral, unoperated C-cell were arranged in the normal locations.

This extreme deficit might have been caused in one of 2 ways: either the $\mathrm{C}$-cell is required to organize the oblique muscle layer, or the $\mathrm{C}$-cell is a myoblast that ultimately gives rise to the oblique muscle cells. The second alternative seemed unlikely because of the highly differentiated appearance of the C-cell, and was largely eliminated by injecting HRP into C-cells in whole, living embryos at 11 and $12 \mathrm{~d}$ of embryogenesis (Weisblat et al., 1978) and examining the animals after 2-4 d of development. In each case ( $n=16 \mathrm{C}$-cells in 6 animals), HRP reaction product was limited to the $\mathrm{C}$-cell, and none was visible in oblique muscle cells, which could be seen using DIC optics. This result indicates that the muscle cells could not have arisen from the C-cell any time after the injections.

\section{Discussion}

Most investigations of muscle development have focused on the cellular and biochemical events involved in the differentiation of muscle cells, such as the fusion of myoblasts and splitting of myotubes into muscle fibers, the production of muscle-associated molecules, and the differentiation of physiological and biochemical fiber types (Fambrough, 1976; Pearson and Epstein, 1982; Bennett, 1983). The question addressed in this study is how a complex muscle mass comes to be organized in a particular, highly stereotyped fashion. This general and fundamental developmental aspect of a muscle's identity would seem to be crucial for behavioral function in the mature animal. 
We have shown here that in each hemisegment of the leech, a highly ordered array of muscle fascicles is laid down upon a framework composed of the processes from a single, identified cell, the $\mathrm{C}$-cell, in the body wall. The $\mathrm{C}$-cell can be considered to be a dedicated organizer for this muscle, since it does not appear to give rise to muscle cells directly and yet is an absolutc requirement for the formation of the muscle. The immediate source of oblique muscle cells and their fate in animals after having a C-cell ablated is at present unknown. While all muscle cells are thought to arise from the mesodermal (M) teloblast (Weisblat et al., 1984), the terminal lineage of particular muscle cells is currently under investigation. Identifying such a lineage would allow us to address further the mechanism by which a C-cell assembles the oblique muscle layer, as well as to determine to what extent a muscle cell's "identity" is directed by intrinsic or extrinsic cues.

While the C-cell is extreme in its regimented, almost crystalline structure, the developmental theme of generating progressively more complex morphology through cascading cellcell interactions is a common one during embryogenesis (Thiery et al., 1985). Muscle formation in vertebrates involves the migration of somitic muscle precursor cells into appropriate locations (Chevallier et al., 1977; Beresford, 1983), where they proceed to differentiate, as mentioned above. While these later events in muscle differentiation have received considerable attention, there is as yet a relative paucity of information about how a whole muscle is formed (Landmesser, 1980). In other words, how do premuscle cells navigate to the appropriate places and align themsclves into a form consistent with the muscle they are destined to become? The evidence to date has clearly implicated the involvement of extracellular matrix materials in this process (see review by Bennett, 1983), but to a large extent the identity of the cells from which these materials are derived remains elusive.

Certain cells in insects (the "Muscle Pioneers," MPs) with a parallel function to that of the C-cell have been described (Ho et al., 1983). These relatively large cells delineate the insertion points of particular muscle fibers and serve as points of collection for smaller mesodermal cells (Ball and Goodman, 1985a, b; Ball et al., 1985b). The MPs, however, differ from the C-cell in at least 2 respects. First, each individual bundle of muscle cells (a muscle fascicle) requires a separate MP for its formation. Thus, a particular muscle with 10 parallel fascicles would require the earlier appearance of 10 parallel MPs. Each bilateral pair of C-cells, however, organizes the entire segmental complement of 35 distinct oblique fascicles. Second, the muscle cells in insects form when smaller mesodermal cells fuse with the MPs to form a multinucleated cell, which then splits up into differentiated muscle fibers. In contrast, the C-cell remains distinct from the individual oblique muscle cells (Fig. 5) as they align themselves and differentiate (as evidenced by their ability to contract and by Lan 3-14 staining).

Such "organizers" may prove to be ubiquitous. Both the MPs in insects and the C-cell described here in the leech serve comparable functions: they lay down a scaffold during early development-when the terrain is relatively simple-that is subsequently used to organize another structure. The C-cell would appear to be simultaneously one of the simplest and yet the most complex of such cellular organizers, for while one can account for the assembly of an entire muscle by this single cell, its morphology is clearly as complex as the muscle it organizes. Therefore, one aspect of experiments in progress is to examine the intrinsic processes, as well as the cellular and extracellular interactions, involved in the highly regimented growth of C-cell processes during embryogenesis. Clearly, this task is facilitated by having, in any single embryo, at least 44 large, nearly identical cells, each of which sends out about 70 growth cones. Such a system should also prove valuable as a model for testing various hypotheses about the directed navigation of growth cones in vivo.

\section{References}

Ball, E. E., and C. S. Goodman (1985a) Muscle development in the grasshopper embryo. II. Syncytial origin of the extensor tibiae muscle pioneers. Dev. Biol. 111: 399-416.

Ball, E. E., and C. S. Goodman (1985b) Muscle development in the grasshopper embryo. III. Sequential origin of the flexor tibiae muscle pioneers. Dev. Biol. 111: 417-424.

Ball, E. E., R. K. Ho, and C. S. Goodman (1985a) Development of neuromuscular specificity in the grasshopper: Guidance of motoneuron growth cones by muscle pioneers. J. Neurosci. 5: 1808-1819.

Ball, E. E., R. K. Ho, and C. S. Goodman (1985b) Muscle development in the grasshopper embryo. I. Muscles, nerves and apodemes in the metathoracic leg. Dev. Biol. 111: 383-398.

Bennett, M. R. (1983) Development of neuromuscular synapses. Physiol. Rev. 63: 915-1048.

Beresford, B. (1983) Brachial muscles in the chick embryo: The fate of individual somites. J. Embryol. Exp. Morphol. 77: 99-116.

Buller, A., J. Eccles, and R. Eccles (1960) Differentiation of fast and slow muscles in the cat hindlimb. J. Physiol. (Lond.) 150: 399-416.

Butler, J., and E. Cosmos (1981) Differentiation of the avian latissimus dorsi primordium: Analysis of fiber type expression using the myosin ATPase histochemical reaction. J. Exp. Zool. 218: 219-232.

Butler, J., E. Cosmos, and J. Brierly (1982) Differentiation of muscle fiber types in aneurogenic brachial muscles of the chick embryo. $\mathrm{J}$. Exp. Zool. 224: 65-80.

Chevallier, A., M. Kieny, and A. Mauger (1977) Limb-somite relationship: Origin of the limb musculature. J. Embryol. Exp. Morphol. 41: 245-258.

Coggeshall, R. E., and D. W. Fawcett (1964) The fine structure of the central nervous system of the leech, Hirudo medicinalis. J. Neurophysiol. 27: 229-289.

Costello, W. J., and R. J. Wyman (1986) Development of an indirect flight muscle in a muscle-specific mutant of Drosophila melanogaster. Dev. Biol. 118: 247-258.

Crow, M. T., and F. E. Stockdale (1986) Myosin expression and specialization among the earliest muscle fibers of the developing avian limb. Dev. Biol. 113: 238-254.

Denburg, J. L., and Z. Fulop (1982) Formation of the leg neuromuscular system in embryos of the cockroach, Periplaneta americana: I. Light microscope studies. J. Exp. Zool. 219: 323-338.

Dennis, M. J., L. Ziskind-Conhaim, and A. J. Harris (1981) Development of neuromuscular junctions in rat embryos. Dev. Biol. 81 : 266-279.

Fambrough, D. M. (1976) Specificity of nerve-muscle interactions. In Neuronal Recognition, S. Barondes and F. E. Bloom, eds., pp. 2567, Plenum, New York.

Fernandez, J., and G. S. Stent (1982) Embryonic development of the hirudinid leech Hirudo medicinalis: Structure, development and segmentation of the germinal plate. J. Embryol. Exp. Morphol. 72: $71-$ 96.

Gillon, J. W., and B. G. Wallace (1984) Segmental variation in the arborization of identified neurons in the leech central nervous system. J. Comp. Neurol. 228: 142-148.

Harris, A. J. (1981) Embryonic growth and innervation of rat skeletal muscles. I. Neural regulation of muscle fiber numbers. Phil. Trans. R. Soc. [Biol.] 293: 257-277.

Ho, R. K., E. E. Ball, and C. S. Goodman (1983) Muscle pioneers: Large mesodermal cells that erect a scaffold for developing muscles and motoneurones in grasshopper cmbryos. Naturc 301: 66-69.

Jellies, J., and W. B. Kristan, Jr. (1988) An identified cell is required for the formation of a major nerve during embryogenesis in the leech. J. Neurobiol. 19: 153-165.

Jellies, J., C. M. Loer, and W. B. Kristan, Jr. (1987) Morphological 
changes in leech Retzius neurons after target contact during embryogenesis. J. Neurosci. 7: 2618-2629.

Kelly, A. M., and S. I. Zacks (1969) The fine structure of endplate morphogenesis. J. Cell Biol. 42: 154-169.

Landmesser, L. T. (1980) The generation of neuromuscular specificity. Ann. Rev. Neurosci. 3: 279-302.

Lawrence, P. A., and D. L. Brower (1982) Myoblasts from Drosophila wing discs can contribute to developing muscles throughout the fly. Nature 295: 55-57.

Lichtman, J. W., R. S. Wilkinson, and M. M. Rich (1985) Multiple innervation of tonic endplates revealed by activity-dependent uptake of fluorescent probes. Nature 314: 357-359.

Macagno, E. R. (1980) Number and distribution of neurons in the leech segmental ganglion. J. Comp. Neurol. 190: 283-302.

McLennan, I. S. (1983a) The development of the pattern of innervation in chicken hindlimb muscles: Evidence for a specification of nerve-muscle connections. Dev. Biol. 97: 229-238.

McLennan, I. S. (1983b) Neural dependence and independence of myotube production in chicken hindlimb muscles. Dev. Biol. 98: 287294.

Miller, J. P., and A. I. Selverston (1979) Rapid killing of single neurons by irradiation of intracellularly injected dye. Science $206: 702-704$.

Miller, J. B., and F. E. Stockdale (1986a) Clonal analysis of myogenic lineages in avian muscle development. Proc. Natl. Assoc. Sci. USA 83: $3860-3864$

Miller, J. B., and F. E. Stockdale (1986b) Developmental regulation of the multiple myogenic cell lineages in the avian embryo. J. Cell Biol. 103: 2197-2208.

Miller, I. B., and F. E. Stockdale (1987) What muscle cells know that nerves don't tell them. Trends Neurosci. 10: 325-329.

Muller, K. J., J. G. Nicholls, and G. S. Stent (1981) Neurobiology of the Leech, Cold Spring Harbor Laboratory, New York.

Ontell, M. (1977) Neonatal muscle: An electron microscopic study. Anat. Rec. 189: 669-690.

Ontell, M., and R. F. Dunn (1978) Neonatal muscle growth: A quantitative study. Am. J. Anat. 152: 539-556.

Ort, C. A., W. B. Kristan, Jr., and G. S. Stent (1974) Neuronal control of swimming in the medicinal leech. II. Identification and connections of motor neurons. J. Comp. Physiol. 94: 121-154.

Pearson, M. L., and H. F. Epstein (1982) Muscle Development, Cold Spring Harbor Laboratory, New York.

Rubinstein, N. A., and A. M. Kelly (1978) Myogenic and neurogenic contributions to the development of fast and slow twitch muscles in the rat. Dev. Biol. 62: 473-485.
Rubinstein, N. A., and A. M. Kelly (1981) Development of muscle fiber specialization in the rat hindlimb. J. Cell Biol. 90: 128-144.

Sanes, J. R. (1987) Cell lineage and the origin of muscle fiber types Trends Ncurosci. 10: 219-221.

Sawyer, R. T. (1986) Leech Biology and Behaviour. I. Anatomy, Physiology and Behaviour, Oxford U. P., New York.

Schafer, D. A., J. B. Miller, and F. E. Stockdale (1987) Cell diversification within the myogenic lineage: In vitro generation of two types of myoblasts from a single myogenic progenitor cell. Cell 48: 659670.

Stent, G. S., D. A. Weisblat, S. S. Blair, and S. L. Zackson (1982) Cell lineage in the development of the leech nervous system. In Neuronal Development, N. C. Spitzer, ed., pp. 1-44, Plenum, New York.

Stewart, W. W. (1978) Functional connections between cells as revealed by dye-coupling with a highly fluorescent napthalamide tracer. Cell 14: 741-759.

Stockdale, F. E., and H. Holtzer (1961) DNA synthesis and myogenesis. Exp. Cell Res. 24: 508-520.

Stuart, A. E. (1969) Excitatory and inhibitory motoneurons in the central nervous system of the leech. Science 165: 817-819.

Stuart, A. E. (1970) Physiological and morphological properties of motoneurones in the central nervous system of the leech. J. Physiol. (Lond.) 209: 627-646.

Thiery, J. P., J. L. Duband, and G. C. Tucker (1985) Cell migration in the vertebrate embryo: Role of cell adhesion and tissue environment in pattern formation. Annu. Rev. Cell Biol. 1: 91-113.

Torrence, S. A., and D. K. Stuart (1986) Gangliogenesis in leech embryos: Migration of neural precursor cells. J. Neurosci. 6: 2736-2746.

Tulsi, R. S., and R. E. Coggeshall (1971) Neuromuscular junctions on the muscle cells in the central nervous system of the leech Hirudo medicinalis. J. Comp. Neurol. 141: 1-16.

Vogel, M., and L. T. Landmesser (1987) Distribution of fiber types in embryonic chick limb muscle innervated by foreign motoneurons. Dev. Biol. 119: 481-495.

Weisblat, D. A., R. T. Sawyer, and G. S. Stent (1978) Cell lineage analysis by intracellular injection of a tracer enzyme. Science 202 . $1295-1298$.

Weisblat, D. A., S. Y. Kim, and G. S. Stent (1984) Embryonic origins of cells in the leech Helobdella triserialis. Dev. Biol. 104: 65-85.

Zipser, B., and R. McKay (1981) Monoclonal antibodies distinguish identifiable neurones in the leech. Nature 289: 549-554. 